\title{
COMPARISON OF OPTICAL BIOMETRY AND A SCAN FOR CALCULATION OF INTRAOCULAR LENS POWER IN AGE RELATED NUCLEAR CATARACT AT TERTIARY CARE EYE HOSPITAL
}

\author{
Aisha Rafique, Omar Zafar, Summaya Khan \\ Armed Forces Institute of Ophthalmology/National University Medical Sciences (NUMS) Rawalpindi Pakistan
}

\begin{abstract}
Objective: To compare optical biometry and A-scan for calculating intraocular lens power in patients with nuclear cataract at tertiary care eye hospital.

Study Design: Cross sectional comparative study.

Place and Duration of Study: Armed Forces Institute of Ophthalmology, Pak Emirates Military Hospital, Rawalpindi, from Jul to Dec 2018.

Methodology: In this study 70 eyes of 70 patients planned for cataract surgery by phacoemulsification underwent both optical biometry with intraocular lens master and ultrasound biometry applanation by A-scan after informed consent. Intraocular lens power calculated by these two methods of biometry was compared. Phacoemulsification surgery was performed through a $2.3 \mathrm{~mm}$ superior temporal clear corneal incision. All patients underwent in-the-bag implantation of the same intraocular lens type.

Results: The mean age of the patients was $62.89 \pm 6.69$ years. A significant ( $p$-value $<0.001)$ difference in intraocular lens power calculation was noted $(20.96 \pm 1.76$ vs. $22.03 \pm 1.61)$ with optical biometry and A-scan respectively. Association on the basis of age groups showed a significant $(p$-value $<0.001)$ difference in both strata that was among patients having age $\leq 65$ years and patients having age $>65$ years.

Conclusion: Optical biometry was found efficient and safe method for calculation of intraocular lens power. Optical biometry is noncontact method having very less chance of infection and suitable for most of the eye types.
\end{abstract}

Keywords: A-scan, Cataract surgery, Intraocular lens power calculation, Optical biometry.

How to Cite This Article: Rafique A, Zafar O, Khan S. Comparison of Optical Biometry and A Scan for Calculation of Intraocular Lens Power in Age Related Nuclear Cataract at Tertiary Care Eye Hospital. Pak Armed Forces Med J 2021; 71(5): 1828-1832. Doi: https://doi.org/10.51253/pafmj.v71i5.3571

This is an Open Access article distributed under the terms of the Creative Commons Attribution License (https://creativecommons.org/licenses/by-nc/4.0/), which permits unrestricted use, distribution, and reproduction in any medium, provided the original work is properly cited.

\section{INTRODUCTION}

The most commonly performed surgery in ophthalmology is cataract surgery around the globe. The improvements in surgical techniques along with advancement in technology have significantly improved the final refractive outcomes. The success of the outcome mainly depends upon measurement of precise preoperative biometry and calculation of intraocular lents (IOL) power. ${ }^{1}$

In modern cataract surgery, the implantation of IOL is a keystone for the surgery. This surgery has become a standard procedure for not only visual rehabilitation in individuals having cataract but also for refractive surgery to define the visual outcome as cataract surgery is now regarded as a form of refractive surgery. The measurement of accurate ocular parameters including axial length and corneal power and use of this data to calculate IOL lens power is called bio-

Correspondence: Dr Aisha Rafique, Department of Ophthalmology, Armed Forces Institute of Ophthalmology, Rawalpindi Pakistan

Received: 01 Dec 2019; revision received: 18 Feb 2020; accepted: 01 Jun 2020 metry. Precise biometry is thus necessary in avoiding postsurgical refractive surprise. ${ }^{2,3}$

The success of cataract surgery can be determined by final refractive outcome and patient satisfaction. The main biometry parameters for accurate calculation of IOL power are axial length, keratometry, anterior chamber depth as well as use of accurate IOL power calculation formula. ${ }^{4}$

Kaswin et al, found that axial length measurement error was responsible for $54 \%$ error in prediction of refractive outcome after IOL implantation. The errors in keratometric value and incorrect estimation of postoperative effective lens position, attribute to $8 \%$ and $38 \%$ error in refractive outcomes respectively. ${ }^{5}$

There are different methods to measure anterior chamber depth, axial length and lens power including applanation ultrasound (A-scan) and IOL master. The A-scan ultrasound is a traditional technique to measure these biometry parameters. It measures these parameters by producing a high frequency sound wave through a crystal oscillation, which penetrates into the 
eye and reflected back towards the probe after encountering a media interface. The distance between the probe and various structures in the eye is calculated by these echoes. ${ }^{6}$

The axial length, anterior chamber depth and keratometric value is measured by optical biometric device through infrared laser light. The optical biometer uses reflected infrared laser light from internal tissues interfaces to measure these parameters. It measures length of optical path from anterior surface of the cornea to the internal limiting membrane, then this path length is converted into a geometric distance by formulas in IOL master. 7,8

Previously, A-scan biometry has been the most commonly used technique for axial length measurement. Recently optical biometry is a fast, noncontact method reported as a potentially more accurate method than ultrasound biometry. This present study has been planned to compare IOL power calculations as measured by IOL master and A-scan ultrasound biometry in patients who underwent phacoemulsification and, in the bag, IOL implantation for nuclear sclerosis cataract.

\section{METHODOLOGY}

The study was started after taking approval from hospital ethics committee (201/ERC/AFIO dated 2911-19). In this cross-sectional comparative study, a total of 70 patients visiting cataract clinic of Armed Forces Institute of Ophthalmology for cataract surgery were included, from June to December 2018. All the patients identified from OPD or ward were briefly described about purpose of the study and informed written consent was taken prior to include in the study. A total of 70 patients were included in the study using non-probability consecutive sampling technique. The sample size was calculated by using WHO sample size calculator with mean value of IOL power by optical biometry $4.67 \pm 1.25$ and by A-scan a mean value of $10.36 \pm 3.52$. Level of significance of $5 \%$, and power of test $80 \%$ was used in sample size calculation'.

In our study sample 70 eyes underwent optical biometry with IOL master (IOL master 700, Carl Zeiss Meditec, Jena, Germany) followed by biometry with A-scan (Pac Scan 300A, Sonomed USA).

Inclusion Criteria: Eyes of the patients with significant cataract as the only ophthalmic pathology causing significant visual impairment suitable for phacoemulsification and primary in bag implantation of posterior chamber IOL.
Exclusin Criteria: Spherical equivalent (SE) $>6 \mathrm{D}$ and axial length $>26 \mathrm{~mm}$ as measured using Zeiss IOL master or A scan biometry. Patients having eyes with other ophthalmic pathology like glaucoma, retinal detachment, age related macular degeneration or ocular inflammation, amblyopia, macular degeneration and patient having history of corneal and refractive surg-ery. Patients presented with corneal opacities or irre-gularities were also excluded from the study.

All patients were subjected to detailed history taking and complete ocular examination including visual acuity (VA), best corrected visual acuity (BCVA), intraocular pressure measurements (IOP), detailed anterior segment and posterior segment examination. All information was recorded on a predesigned proforma. Biometry was first performed using optical biometer and followed by ultrasound biometry. This sequence of biometry was considered to maintain clarity of corneal epithelium which may inadvertently be compromised due to applanation by ultrasound A scan probe. Keratometry readings ( $\mathrm{K}$ readings) were taken from automated refractometer to be used in A scan IOL power calculation. IOL master has in built programming to calculate $\mathrm{K}$ readings. IOL power calculation was obtained initially with IOL master followed by ultrasound biometry by same investigator. IOL power calculated by these two methods was then compared. Optical biometry was performed with the patient seated in upright position at the IOL Master and asked to fixate on the internal fixation target. An applanation ultrasound using A scan was performed after instillation of one drop of surface anesthetic (proparacaine hydrochloride $0.5 \%$ ) on the lower forniceal conjunctiva. After which patient was asked to look straight ahead and transducer was held at center of cornea so that the ultrasound beam is perpendicular to globe. Theoretic IOL prediction formula (SRK/T) was used to calculate IOL power, emmetropia was aimed after surgery. Phacoemulsification surgery was performed through a $2.3 \mathrm{~mm}$ superior temporal clear corneal incision. All patients underwent in the bag implantation of the same IOL type.

All the collected data was entered and analyzed in SPSS-21. Descriptive statistics were used to calculate mean with standard deviation for quantitative data and frequency and percentages for qualitative data. Paired sample t-test was applied to compare mean values of IOL power measured by IOL master and A-scan ultrasound. The $p$-value $\leq 0.05$ was considered significant. Post stratification paired t-test was applied to 
observe the effect of age and gender on IOL power calculation with both techniques.

\section{RESULTS}

In this study a total of 70 patients were enrolled. Descriptive statistics of patient characteristics were given in Table-I. The comparison of IOL power calculated by optical biometry and A-scan showed a highly significant ( $p$-value <0.001) difference in IOL power calculation as elaborated shown in the Table-II.

Table-I: Descriptive statistics of patient characteristics.

\begin{tabular}{l|c|c}
\hline Characteristics & Frequency & Percentage \\
\hline Age of Patients (years) & \multicolumn{2}{|c}{$62.89 \pm 6.69$} \\
\hline Mean \pm SD & 42 & $60 \%$ \\
\hline$\leq 65$ years & 28 & $40 \%$ \\
\hline$>65$ years & 58 & $82.9 \%$ \\
\hline Gender of Patients & 12 & $17.1 \%$ \\
\hline Male & 5 & $7.1 \%$ \\
\hline Female & 65 & $92.9 \%$ \\
\hline Type of Cataract & \multicolumn{2}{|c}{$20.96 \pm 1.76$} \\
\hline Nuclear Sclerosis-1 & $\mathbf{n}=35)$ \\
\hline Nuclear Sclerosis-2 & $22.03 \pm 1.61$ \\
\hline Intraocular lens IOL Power by Optical Biometry \\
\hline Mean \pm SD \\
\hline Intraocular lens IOL Power by A-Scan (n=35) \\
\hline Mean \pm SD
\end{tabular}

Table-II: Comparison of intraocular lens IOL power by optical biometry and A-Scan.

\begin{tabular}{|c|c|c|c|}
\hline Stratification & IOL Power & $\begin{array}{l}\text { Mean } \pm \\
\text { SD }\end{array}$ & $\begin{array}{c}p \text { - } \\
\text { value }\end{array}$ \\
\hline \multicolumn{4}{|c|}{ Overall Comparison } \\
\hline \multirow{2}{*}{ Over all } & $\begin{array}{l}\text { IOL Power by Optical } \\
\text { Biometry }(n=35)\end{array}$ & $\begin{array}{l}20.96 \pm \\
1.76\end{array}$ & \multirow{2}{*}{$<0.01$} \\
\hline & $\begin{array}{l}\text { IOL Power by } \\
\text { A-Scan }(n=35)\end{array}$ & $\begin{array}{c}22.03 \pm \\
1.61\end{array}$ & \\
\hline \multicolumn{4}{|c|}{ Gender of the Patients } \\
\hline \multirow{2}{*}{ Male } & $\begin{array}{c}\text { IOL Power by Optical } \\
\text { Biometry }\end{array}$ & $\begin{array}{c}20.88 \pm \\
1.82 \\
\end{array}$ & \multirow{2}{*}{$<0.01$} \\
\hline & $\begin{array}{l}\text { IOL Power by } \\
\text { A-Scan }\end{array}$ & $\begin{array}{c}21.97 \pm \\
1.62\end{array}$ & \\
\hline \multirow{2}{*}{ Female } & $\begin{array}{c}\text { IOL Power by Optical } \\
\text { Biometry } \\
\end{array}$ & $\begin{array}{c}21.33 \pm \\
1.50\end{array}$ & \multirow{2}{*}{$<0.01$} \\
\hline & $\begin{array}{l}\text { IOL Power by } \\
\text { A-Scan }\end{array}$ & $\begin{array}{c}22.33 \pm \\
1.56\end{array}$ & \\
\hline \multicolumn{4}{|c|}{ Age Groups of Patients } \\
\hline \multirow{2}{*}{$\leq 65$ years } & $\begin{array}{l}\text { IOL Power by Optical } \\
\text { Biometry }\end{array}$ & $\begin{array}{c}20.62 \pm \\
1.55\end{array}$ & \multirow{2}{*}{$<0.01$} \\
\hline & $\begin{array}{c}\text { IOL Power by } \\
\text { A-Scan }\end{array}$ & $\begin{array}{c}21.71 \pm \\
1.50\end{array}$ & \\
\hline \multirow{2}{*}{$>65$ years } & $\begin{array}{c}\text { IOL Power by Optical } \\
\text { Biometry }\end{array}$ & $\begin{array}{c}21.46 \pm \\
1.97\end{array}$ & \multirow{2}{*}{$<0.01$} \\
\hline & $\begin{array}{l}\text { IOL Power by } \\
\text { A-Scan }\end{array}$ & $\begin{array}{c}22.50 \pm \\
1.67\end{array}$ & \\
\hline
\end{tabular}

\section{DISCUSSION}

Implantation of an IOL is the cornerstone in modern day cataract surgery, which is not only used for just visual rehabilitation but has also become a form of refractive surgery in which the final refractive result can define visual outcome. Accurate biometry necessitates a proper axial lens measurement which is most important influencing factor of IOL power calculation. ${ }^{10}$ However, precise biometry prediction in extremely short and long eyes has always been difficult. ${ }^{11}$

In cataract surgery, optical biometry by partial coherence interferometry (IOL master) has proved to be more precise and safer for IOL power calculation and better refractive outcome. The IOL master also has the advantage of non-contact with eyes and accurate measurement of axial length, which in case of A-scan can be compromised because A-scan measurement requires eye contact with probe and in some cases, the measurement of axial length might be erroneous. ${ }^{12}$ All the biometric parameters can be measured with IOL master, which are used to calculate IOL power with various formulas. The use of dual beam coherence interferometry by IOL master further improves the refractive outcome in patients of cataract surgery. ${ }^{13}$

IOL power calculation is essential to get satisfactory outcome after cataract surgery. At present, optical biometry with the IOL master is considered the gold standard for AL measurements and IOL power due to its good reproducibility and accuracy. The studies on evaluation of efficacy of A-scan and IOL master are limited. Optical biometer is a newer technique and few studies have compared it with applanation biometry. The results of these studies are contradictory with studies of Ha et al, and Huang et al who concluded that A-scan can provide equaling biometric data and IOL power calculation in cataract surgery patients. ${ }^{14,15}$

However, the result of some studies has suggested that refractive outcomes obtained on the basis of optical biometry are superior as compared to ultrasound biometry especially in myopia, posterior staphyloma or eyes with silicone oil filled cavity which are regularly measured with IOL master using option of "SO filled eye" already available in IOL master programming. Ultrasound biometry has several fallacies in SO filled eye because of multiple fluid filled interfaces and poor penetration due to sound being absorbed by oil. ${ }^{16}$

The results of this study showed that the IOL power calculated by optical biometry and A-scan had a significant ( $p$-value $<0.001)$ difference in IOL power cal- 
culation with a mean IOL power value of $20.96 \pm 1.76$ $\mathrm{D}$, with optical biometry and $22.03 \pm 1.61 \mathrm{D}$, by A-scan.

According to the results of this study, stratification on the basis of gender showed that there was still significant ( $p$-value $<0.001)$ difference in IOL power calculation by optical biometry and A-scan among males and females. This stratified difference on the basis of gender was although less than overall difference but it was statistically significant. Stratification was also done on the basis of age groups and IOL power calculation was significantly ( $p$-value $<0.001$ ) different in both strata that is among patients having age $\leq 65$ years and patients having age $>65$ years. Indicating that there is no effect of gender or age on the IOL power calculation with optical biometry and A-scan. These results are also in agreement with other studies comparing both methods of IOL power calculation. ${ }^{17-19}$

The process of ocular biometry has become simplified with IOL master. Since IOL master is noncontact technique, so topical anesthesia is not required. This non-contact technique increases the comfort of patient especially elderly patients and minimizes the chance of infection transmission and corneal abrasions. The measurement of IOL is more accurate with optical biometry as compared with A-scan the patient fixates at measurement beam in the device whereas in ultrasound biometry by A scan misalignment between measured axis and visual axis results in erroneously longer axial lengths leading to increased calculated IOL power causing postoperative myopia. This is especially important in eyes with posterior pole staphyloma, because of the more precise localization of the fovea. ${ }^{20,21}$ Sources of subjective error is therefore markedly reduced in measurements by optical biometry. However, there are some situations when results of optical biometry are clear cut poor than ultrasound biometry for example in dense brunescent cataract and geriatric patients who are unable to sit upright. In this stance A-scan become the only choice for measurement of optical biometry, though this typically requires more time, extra training and a higher level of patient contact. ${ }^{22,23}$

\section{LIMITATION OF STUDY}

This study can be considered to have two limitations. We did not evaluate all available optical biometers, and we did not enroll healthy eyes with clear lenses, for which the results may be different. Repeatability for lens thickness data are lacking for Galilei G6 biometer and for US immersion biometry and will be the target of future studies. Improvement in post-operative refraction and visual outcomes will further aid to compare the superiority and efficacy of one of the two-mentioned biometry.

\section{CONCLUSION}

Optical biometry was found effective method for calculation of IOL power. Optical biometry is noncontact method so less chances of infection. Optical biometry also has the advantage of comfortable position of patient with target light to be presented to patient in machine which makes it easier for the patient to fixate. The A-scan biometry has advantages of cost effectiveness and can be used in very dense cataract.

\section{Conflict of Interest: None.}

\section{Authors' Contribution}

AR: Direct/Intellectual, OZ: Direct contribution to conception/supervision, SK: Intellectual/data analysis.

\section{REFERENCES}

1. Kaswin G, Rousseau A, Mgarrech M, Barreau E, Labetoulle M. Biometry and intraocular lens power calculation results with a new optical biometry device: comparison with the gold standard. J Cataract Refract Surg 2014; 40(4): 593-600.

2. Farahat HGED, Ahmed KES, Marey HMG, Fouad MA. Intraocular lens master optical biometry versus conventional ultrasound biometry in intraocular lens power calculations in highly myopic eyes. Menoufia Med J 2017; 30(2): 485-91.

3. Chia TMT, Nguyen MT, Jung HC. Comparison of optical biometry versus ultrasound biometry in cases with borderline signal-to-noise ratio. Clin Ophthalmol 2018; 12(2): 1757-62.

4. Fontes BM, Fontes BM, Castro E. Intraocular lens power calculation by measuring axial length with partial optical coherence and ultrasonic biometry. Arq Bras Oftalmol 2011; 74(3): 166-70.

5. Srivannaboon S, Chirapapaisan C, Chonpimai M, Koodkaew S. Comparison of ocular biometry and intraocular lens power using a new biometer and a standard biometer. J Cataract Refract Surg 2014; 40(1): 709-15.

6. Lee AC, Qazi MA, Pepose JS. Biometry and intraocular lens power calculation. Curr Opin Ophthalmol 2008; 19(1): 13-17.

7. Wang JK, Chang SW. Optical biometry intraocular lens power calculation using different formulas in patients with different axial lengths. Int J Ophthalmol 2013; 6(2): 150-154.

8. Bang S, Edell E, Yu Q, Pratzer K, Stark W. Accuracy of intraocular lens calculations using the IOL master in eyes with long axial length and a comparison of various formulas. Ophthalmol 2011; 118(3): 503-506.

9. Farahat HGD, Ahmed KES, Marey HMG, Fouad MA. Intraocular lens master optical biometry versus conventional ultrasound biometry in intraocular lens power calculations in highly myopic eyes. Menoufia Med J 2017; 30(2): 485-491.

10. El Samadony MA, Hafez TA, Helaly HA, Rafik MM. Comparison of predictability of intraocular lens power calculation formulas for axial hyperopic patients undergoing cataract surgery using intraocular lens master. Egypt J Cataract Refract Surg 2017; 23(2): 49-53.

11. Sahin A, Hamrah P. Clinically relevant biometry. Curr Opin Ophthalmol 2012; 23(1): 47-53.

12. Ladas JG, Stark WJ. Improving cataract surgery refractive outcomes. Ophthalmol 2011; 118(9): 1699-700.

13. Chen YA, Hirnschall N, Findl O. Evaluation of 2 new optical biometry devices and comparison with the current gold standard biometer. J Cataract Refract Surg 2011; 37(3): 513-517.

14. Ha A, Wee WR, Kim MK. Comparative efficacy of the new optical biometer on intraocular lens power calculation (AL-Scan versus IOL Master). Korean J Ophthalmol 2018; 32(3): 241-248. 
15. Huang J, Savini G, Li J. Evaluation of a new optical biometry device for measurements of ocular components and its comparison with IOL Master. Br J Ophthalmol 2014; 98(9): 12771281.

16. Gaballa SH, Allam RSHM, Abouhussein NB, Raafat KA. IOL master and A-scan biometry in axial length and intraocular lens power measurements. Delta J Ophthalmol 2017; 18(1): 13-19.

17. Roy A, Das S, Sahu SK, Rath S, Odisha B. Ultrasound biometry vs. IOL Master. Ophthalmol 2012; 119(9): 1937-1942.

18. Gopi R, Sathyan S. Comparison of ocular biometry parameters between IOL Master and applanation A-scan in eyes with short, medium, long, and very long axial lengths. Kerala J Ophthalmol 2017; 29(1): 35-40.
19. Turczynowska M. Effective ocular biometryand intraocular lens power calculation. Eur Ophthalmic Rev 2016; 10(2): 94-100.

20. Kunavisarut P, Poopattanakul P. IOL master and A-scan biometry in silicone oil-filled eyes. Eye 2012; 26(10): 1344-1348.

21. Atwa FA, Kamel HS, Kamel RM, Abd-El-Fatah AA. Refractive outcome after phacoemulsification using optical biometry versus immersion ultrasound biometry. Egypt J Hospital Med 2019; 75(5): 2806-2812.

22. Goebels SC, Seitz B. Reproducibility of the optical biometer OA1000 (Tomey). Biomed Res Int 2014; 2014(1): 814761.

23. Goebels S, Pattmöller M, Eppig T, Cayless A, Seitz B, Langenbucher A. Comparison of 3 biometry devices in cataract patients. J Cataract Refract Surg 2015; 41(11): 2387-2393. 